\title{
LED Based Optical Wireless Communication System for WBAN
}

\author{
ATTIYA BAQAI*, FAHIM AZIZ UMRANI*, AND BHAWANI SHANKAR CHOWDHRY* \\ RECEIVED ON 26.04.2016 ACCEPTED ON 16.08.2016
}

\begin{abstract}
In this paper the O-WBANs (Optical Wireless Body Area Networks) is presented as an alternative to the radio and microwave BANs which are plagued with issues like interference, power hungry, hazardous and costly spectrum. Various experiments performed in this work demonstrate the feasibility of LED (Light-Emitting Diode) based optical systems to be used for BANs. The system cost is kept as low as possible. Mainly the effects on the optical link are observed under ambient light and with different modulation schemes by varying link distance and line of sight in this paper. Experimental results reveal the satisfactory link availability up to the distance of 7 feet (around 2m, the optimum range of WBAN) and within the field of view of $30-60^{\circ}$. The low cost solution presented in this paper meets the WBANs data rate requirement for physiological data (i.e. 10-100 kbps). As IR (Infra-Red) signals do not provide any interference with the signals generated by the medical equipment of hospitals which is the problem in case of RF or microwave signals, additionally the IR signals are confined within a room hence IR signaling can prove to be potential candidate for WBAN fulfilling its security and limited access requirement.
\end{abstract}

Key Words: Infrared, Free-Space Optical Communication, Modulation, Optical Communications.

\section{INTRODUCTION}

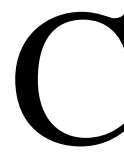
urrently, majority of the WBANs rely on the radio and microwave based technologies designed for the short range personal area networks. Chakraborty, et. al. [1] compares various standards and technologies along with their specifications available for WBAN. Hanlen, et. al. [2], and Bilstrup [3] discusses several QoS (Quality of Service) issues in existing WBANs. Existing deployed technologies for WBAN do not necessarily take into account the special requirements posed by WBANs. Several benefits can be achieved by optical wireless communication using LED including lower cost, low power, no EMI (Electromagnetic Interference), unregulated spectrum, and extremely enhanced security.
Boucouvalas, et. al. [4] discusses the existing standards of OWC, trends and future directions for Indoor Optical Wireless Communications.

With little additional cost the LEDs, apart from providing lighting, can also be used as a source of data communications [5-10]. Furthermore, in our previous work [10], it is argued that the optical signaling schemes inherently compliment the security, low cost and interference free requirement of WBANs with a protocol designed for WBAN using infrared signaling. Getting motivation from this fact, we present in this paper an LED based optical WBAN.

* Institute of Information \& Communication Technologies, Mehran University of Engineering \& Technology, Jamshoro.

Mehran University Research Journal of Engineering \& Technology, Volume 35, No. 4, October, 2016 [p-ISSN: 0254-7821, e-ISSN: 2413-7219] 
In order to implement Optical Wireless Communication system practically using LED several challenges are to be dealt with. As discussed in [11,12], at higher frequencies the response of LED is limited supporting only few $\mathrm{MHz}$ Using VLC (Visible Light Communications) the authors in [11] achieve the transmission distance up to 1.7 meters with $160^{\circ}$ field of view and transmission data rate of 100 KHz. They applied simple NRZ data while keeping the lighting fixed. In [13], the authors have used Manchester coding to discuss the experimental results for the LED to reduce optical noise. They have not used any adaptive monitoring, feedback or optical filtering. The LOS link length is 1.65 meters with fixed illumination level supporting data rates of 1.25 and $2.5 \mathrm{Mb} / \mathrm{s}$. Also they have used a pair of focusing lens and an amplifier rendering the design expensive. In [14], some experiments and hardware options to increase transmission distance and data rate are discussed. Their achieved data rate and distance are $1.2 \mathrm{kbps}$ and 1 foot respectively with simple NRZ ASCII (American Standard Code for Information Interchange) coding. Choi, et. al. [15] uses microwave system using ASK modulation to achieve data rates of $100 \mathrm{~kb} / \mathrm{s}$ at a distance of 1 meter. Prince and Vibin [16] has established an LED based wireless audio communication system with $100 \mathrm{KHz}$ audio signal. They performed experiments to test the link reliability with different angles and distances with OOK. Their achieved half power semi angle is $33^{\circ}$ whereas the distance is $3 \mathrm{~m}$. Hussain, et. al. [17] discusses the effect of increasing distance in VLC system as a significant reduction in the data rate. They have tested their transceiver designs for $3 \mathrm{~m}$ link distance and with 2.5 Mbps data rate using OOK and LOS only.

In this paper we present the alternative to the radio and microwave BANs and analyze the O-WBANs by investigating the effects of ambient light, link distance, modulation/encoding schemes and Angle of receiver towards transmitter.

\section{EXPERIMENT}

Fig. 1 shows the experimental set up performed in the room with dimensions as illustrated in Fig. 2.

The carrier wave and Information signal are generated by the function generators which are connected to the balanced modulator which can modulate upto $100 \mathrm{KHz}$ with ASK, FSK, and PSK schemes. The complete transceiver design is shown in Fig. 3. Careful consideration is made in increasing the frequencies of carrier and the information signal to avoid over modulation. The output generated by the balanced modulator is about $600 \mathrm{mV}$, incapable to drive an IR LED of 940nm wavelength directly, so an amplifier is used before LED as shown in Fig. 1. It is observed that with the increase of frequency the LED gets dim making the receiver unable to detect the modulated wave. A silicon based PIN Thor LAB DT100A detector is used as the receiver as shown in Fig. 1. The transceivers are placed on the desk at the center of the lab. In order to perceive the effect on the optical wireless communication link due to light variation the lights present in the room were switched ON and OFF. Table 1 lists the power received and illuminance measured in Lux when specific lights were switched ON and OFF. The received power from PIN photo-detector is measured by Newport Digital power Meter Model 815 which indicates detected light variations in terms of received power. Eye diagrams are plotted on TEKTRONIX TDS2012 Oscilloscope with $100 \mathrm{MHz}$ Bandwidth and $1 \mathrm{GSa} / \mathrm{s}$ sample rate whereas the samples are recorded with DSO GDS-1062 of GW Instek having 20MSa/s sampling, 60MHz bandwidth and 4000 samples memory length.

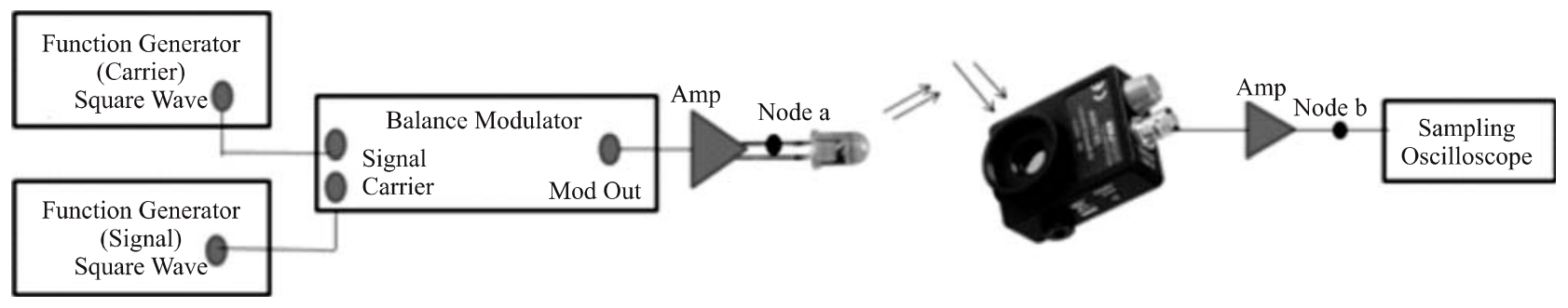

FIG. 1. EXPERIMENTAL SET UP

Mehran University Research Journal of Engineering \& Technology, Volume 35, No. 4, October, 2016 [p-ISSN: 0254-7821, e-ISSN: 2413-7219] 


\section{RESULTS AND DISCUSSION}

Q-factors are used to experimentally evaluate the optical wireless link with different modulation schemes, ambient light and FOV variations. The measured Q-factors are then used to calculate the corresponding BER.

Fig. 4(a-c) shows the effects of switching lights ON for various modulation schemes with the help of eye diagrams which clearly indicates the better performance of FSK. Figs. 5-10 summarize the experimental results and performance for the parameters of Distance, Angle and number of lights turned on through SNR and BER curves.
From Fig. 5, one can observe the degradation of SNR as the distance increases. Except for ASK, all other modulation techniques perform satisfactorily well upto the distance of 7 feet which is more than sufficient for the WBAN. 2-PSK and 4-PSK perform well with the increasing distance under low ambient light; provided the LOS is maintained or kept within a field of view under 20 degrees compared to other modulation schemes. FSK is found to be more tolerant in non-LOS environment as shown in Fig. 6. It performed satisfactorily well within a field of view of $60^{\circ}$. PSK demonstrated the worst performance under non LOS and high ambient light environment as shown in Fig. 7. Among all modulation schemes FSK is

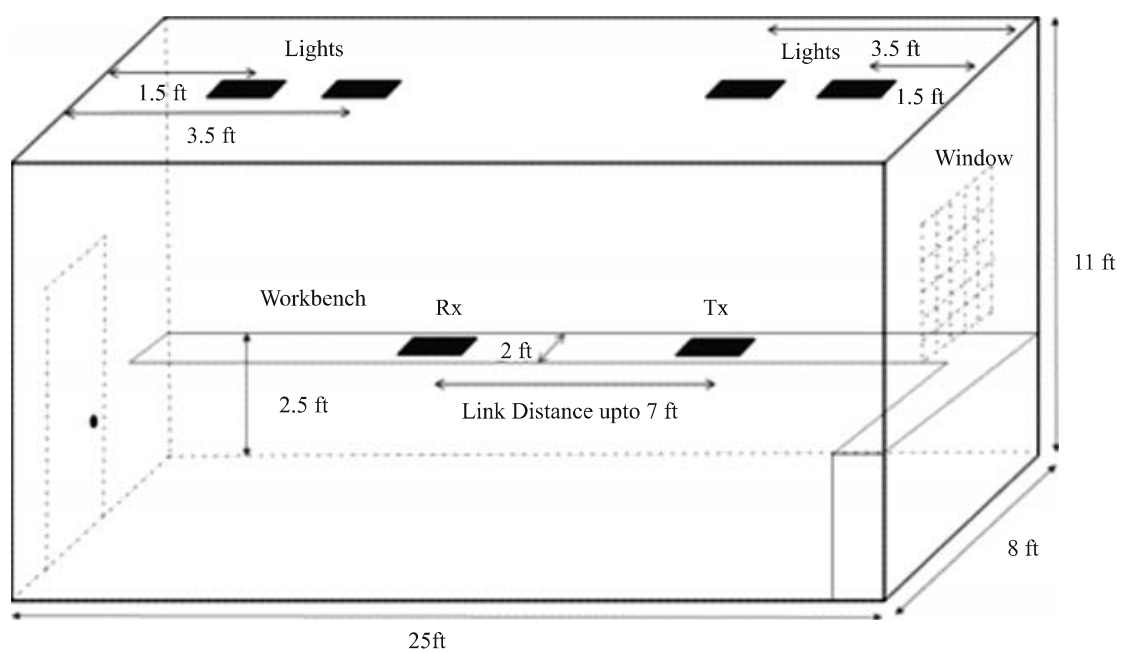

FIG. 2. ROOM DIMENSIONS
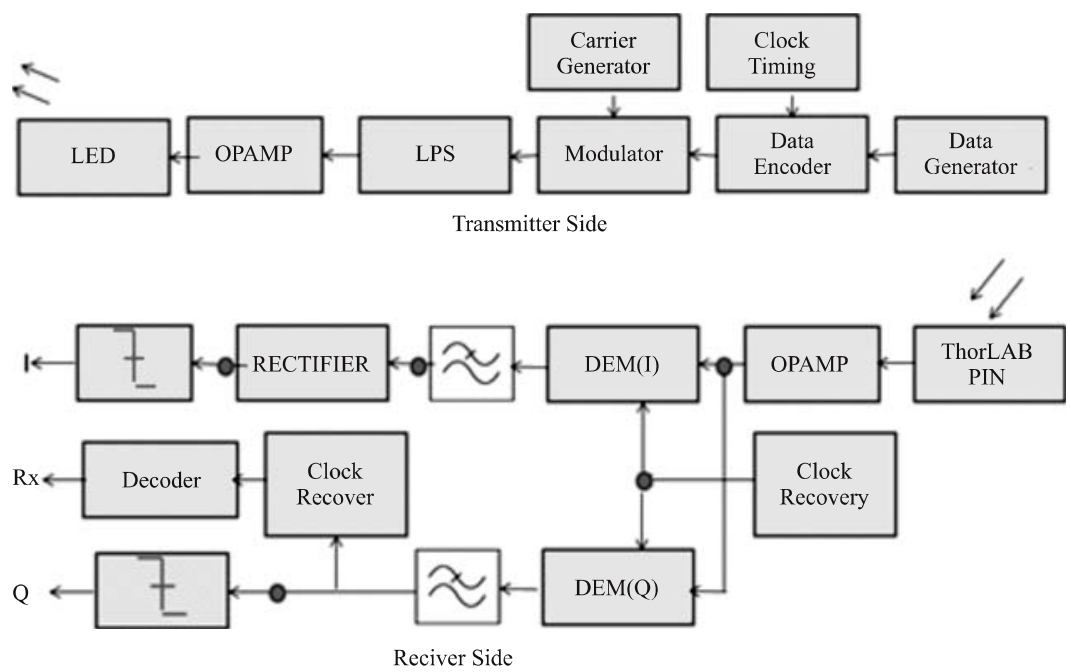

FIG. 3. TRANSCEIVER DESIGN FOR EXPERIMENTAL SETUP

Mehran University Research Journal of Engineering \& Technology, Volume 35, No. 4, October, 2016 [p-ISSN: 0254-7821, e-ISSN: 2413-7219] 
observed to exhibit stable response. Fig. 8-10 shows the SNR versus BER curves for the three cased discussed above.

Data rate is tested using a binary ASK modulation. The required data rate of $100 \mathrm{~kb} / \mathrm{s}$ for WBAN is succeeded with the link established in this paper. It is observed that the LED brightness is reduced with the increase in carrier frequency making the receiver unable to detect the modulated wave. For example, the amplitude of the received modulated signal is of the order of $178 \mathrm{mV}$ peak to peak in Fig. 11(a) and $168 \mathrm{mv}$ in Fig. 11(b) with $300 \mathrm{KHz}$ carrier. This voltage is significantly reduced to $74 \mathrm{mV}$ peak to peak at a carrier of $1 \mathrm{M} \mathrm{Hz}$. Though the low data rate achieved is sufficient for BANs it can easily be improved with multiple stages of amplifiers at transmitter and receiver side. The data rate can also be improved with thresholding circuits at the receiver side after the amplification stage and filtering the noise.

TABLE 1. POWER RECEIVED AND ILLUMINANCE MEASUREMENT

\begin{tabular}{|c|c|c|c|}
\hline No. & $\begin{array}{c}\text { No. of Lights } \\
\text { ON }\end{array}$ & $\begin{array}{c}\text { Power Received } \\
(\mathrm{mW})\end{array}$ & $\begin{array}{c}\text { Illuminance } \\
(\text { Lux })\end{array}$ \\
\hline 1. & None & 0 & $0-2$ \\
\hline 2. & One & 0.62 & $4-6$ \\
\hline 3. & Two & 0.72 & $8-14$ \\
\hline 4. & Three & 1.44 & $16-20$ \\
\hline 5. & Four & 1.84 & $34-39$ \\
\hline
\end{tabular}

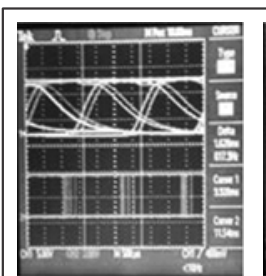

(a)

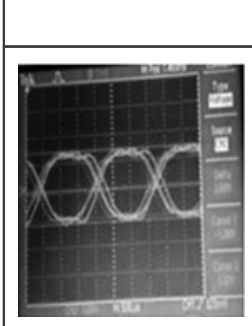

(a)

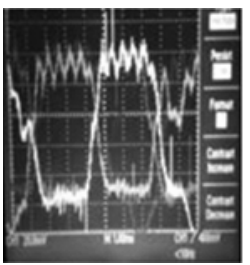

(b)

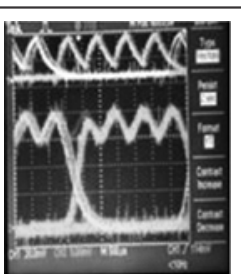

(c)

Amplitude Shift Keying

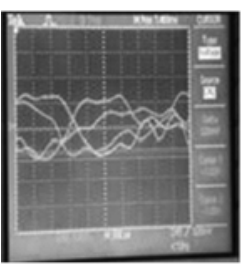

(b)

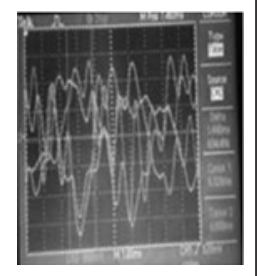

(c)

2-Phase Shift Keying

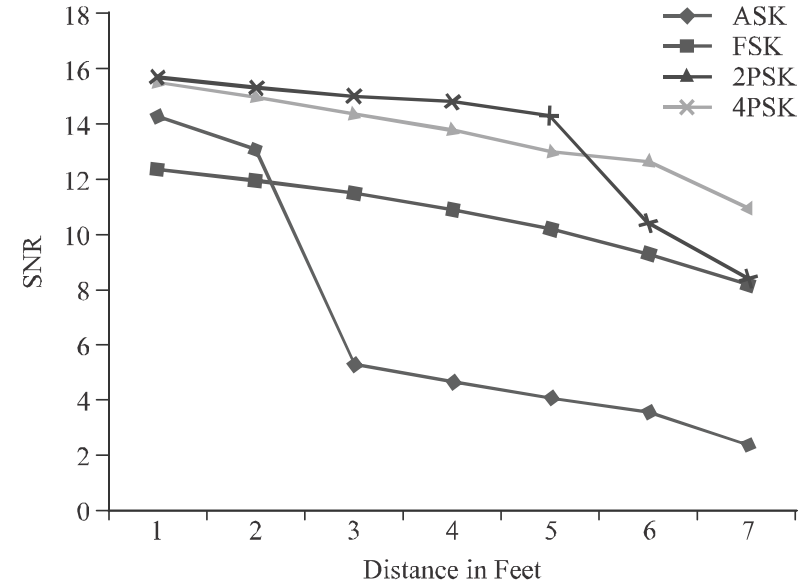

FIG. 5. EFFECT OF INCREASING DISTANCE ON SNR WITH DIFFERENT MODULATION SCHEMES (WITH NO LIGHTS

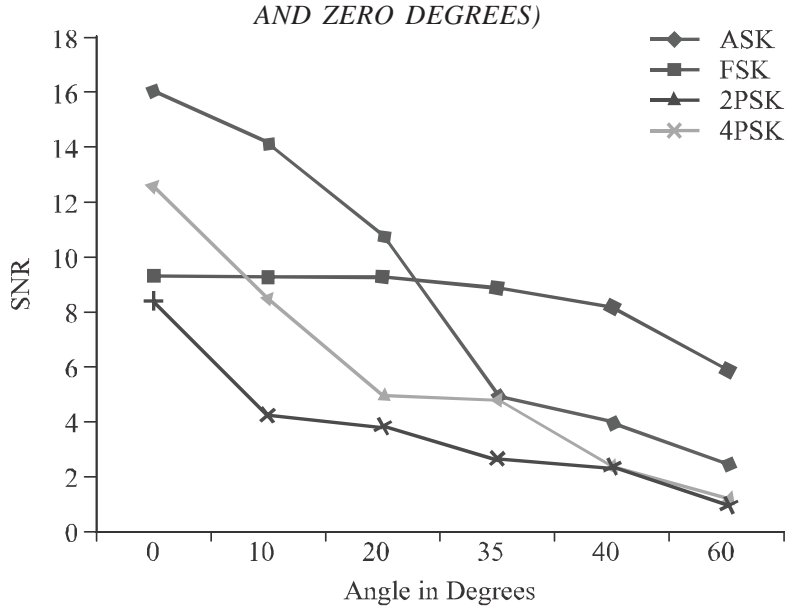

FIG. 6. EFFECT OF INCREASING ANGLE DEVIATION ON SNR WITH DIFFERENT MODULATION SCHEMES(TWO LIGHTS, 3 FEET)

FIG. 4. EYE DIAGRAMS FOR ASK, FSK, 2-PSK AND 4-PSK (A) NO LIGHTS (B) TWO LIGHTS (C) FOUR LIGHTS 


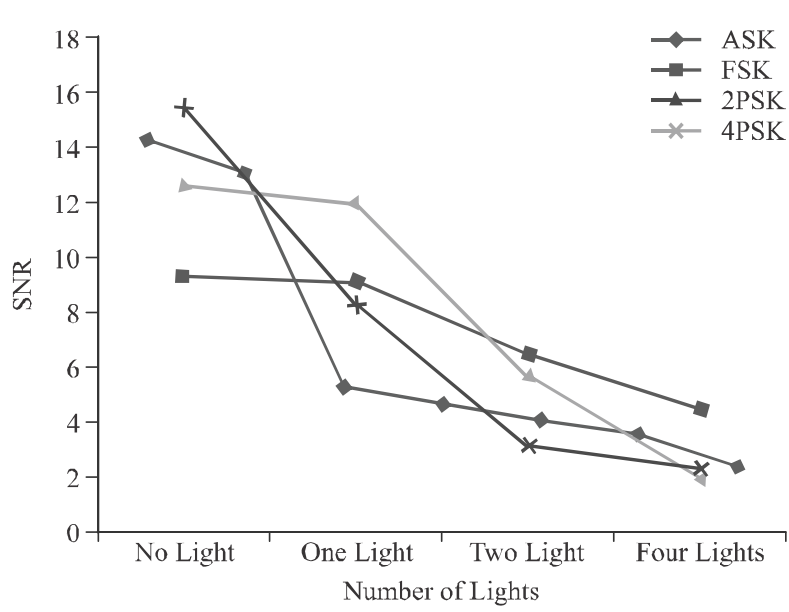

FIG. 7. EFFECT OF INCREASING NO OF LIGHTS ON SNR WITH DIFFERENT MODULATION SCHEMES(3FT,ZERO DEGREES)

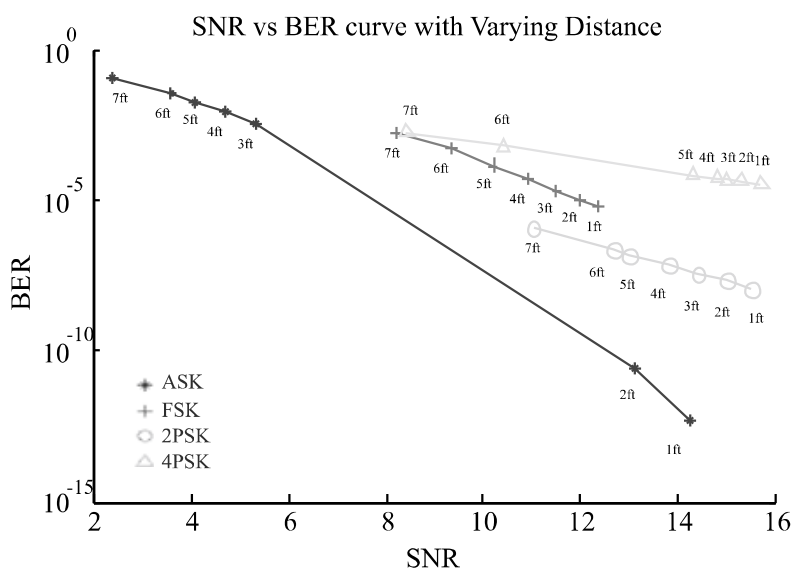

FIG. 8. SNR VS BER CURVE WITH VARYING DISTANCE FOR DIFFERENT MODULATION SCHEMES

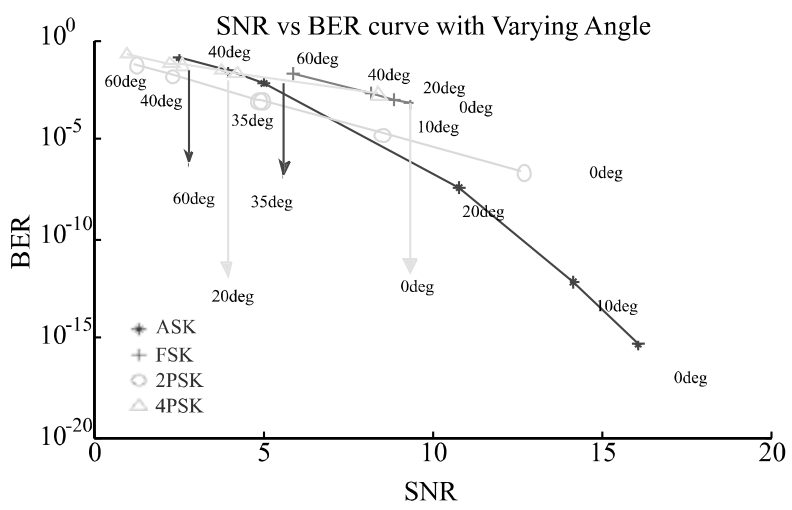

FIG. 9. SNR VS BER CURVE WITH VARYING ANGLE FOR DIFFERENT MODULATION SCHEMES

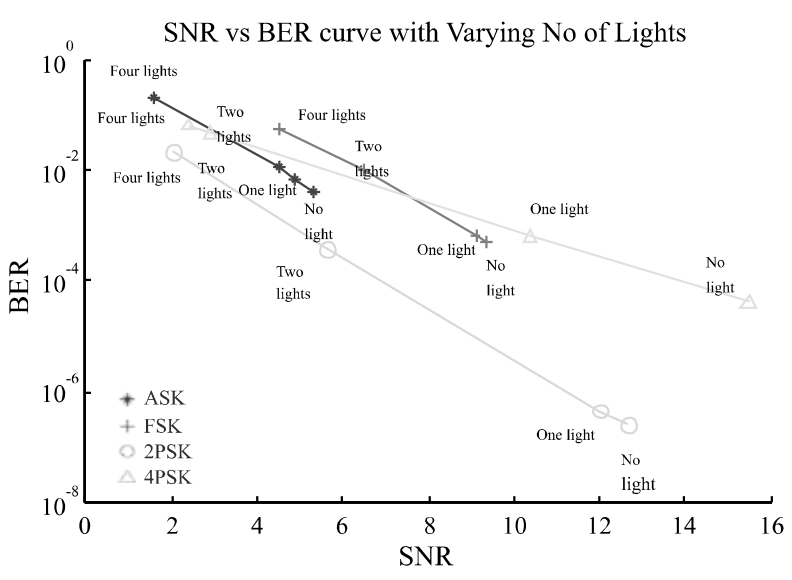

FIG. 10. SNR VS BER CURVE WITH VARYING NUMBER OF LIGHTS FOR DIFFERENT MODULATION SCHEMES

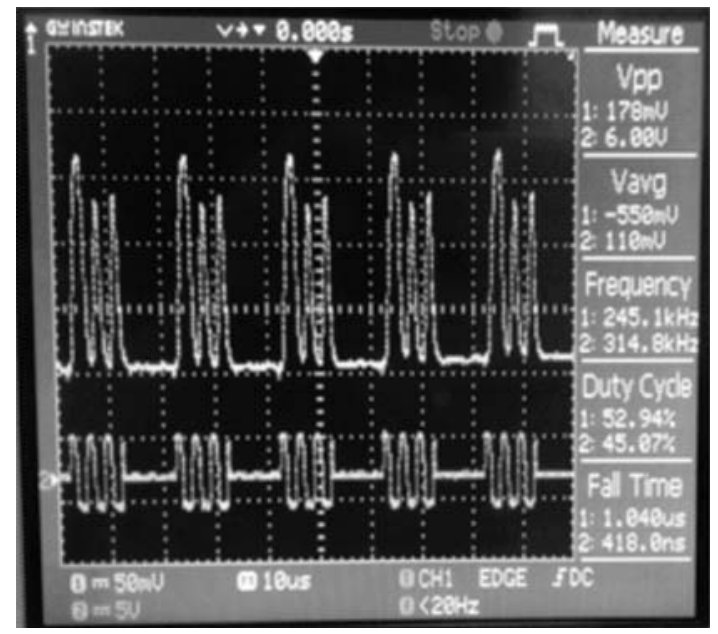

(a) $f_{m}=50 \mathrm{KHz} f_{c}=300 \mathrm{kHz}$, Data Rate of $50 \mathrm{~kb} / \mathrm{s}$

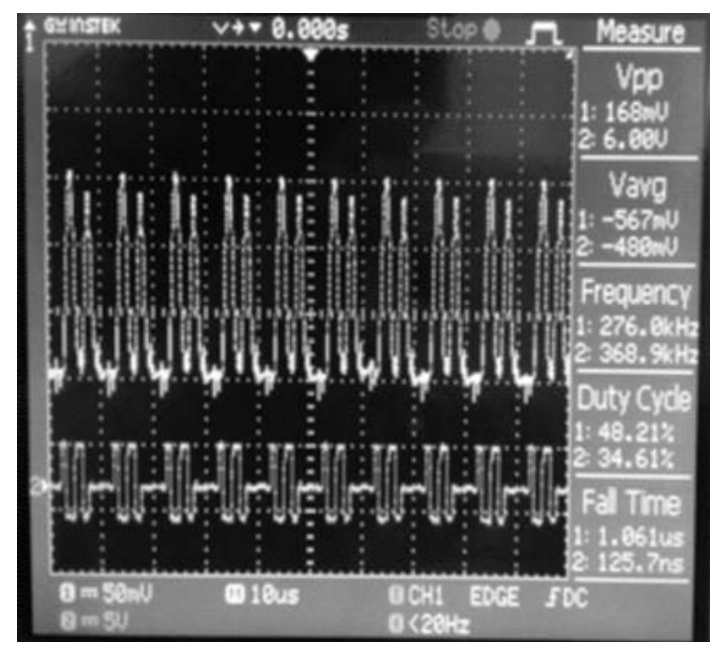

(b) $f_{m}=100 \mathrm{KHz} f_{c}=300 \mathrm{kHz}$, Data Rate of $100 \mathrm{~kb} / \mathrm{s}$

FIG. 11. TRANSMITTED (BOTTOM) AND RECEIVED (TOP) SIGNALS (A) DATA RATE $50 \mathrm{~KB} / \mathrm{S}$ (B) DATA RATE $100 \mathrm{~KB} / \mathrm{S}$ 


\section{CONCLUSION}

In this research work various parameters have been used to analyze the performance of Infra-red link established for WBAN. The parameters discussed here are ambient light, noise, modulation scheme, link distance, data rate and angular displacement of receiver from transmitter's LOS. The results demonstrate that an infra-red link can be used with such configuration for WBAN with sufficient accuracy up to the range of 7 feet (around $2 \mathrm{~m}$ ) and can support data rate up to $100 \mathrm{~kb} / \mathrm{s}$ that is sufficient enough for the physiological waveforms and data which can further be improved. FSK is observed to be the most resilient modulation scheme. During the experiments it was observed that the ambient light effects the system performance severely; justifying the need to invest efforts to explore interference mitigation techniques.

\section{ACKNOWLEDGMENTS}

This work is supported by Institute of Information \& Communication Technologies, Mehran University of Engineering \& Technology Jamshoro, Pakistan, for a Ph.D. project under faculty development program. The Authors are grateful to Department Telecommunication Engineering, Electronics Engineering, for facilitating lab equipment. Special thanks to Engr. Khuhed Memon and Engr. AzamRafique Memon, for their cooperation and assistance.

\section{REFERENCES}

[1] Chakraborty, C., Gupta, B., and Ghosh, S.K., "A Review on Telemedicine-Based WBAN Framework for Patient Monitoring”, Telemedicine e-Health, Volume 19, No. 8, pp. 619-626, 2013.

[2] Hanlen, L., Smith, D., Boulis, A., Gilbert, B., Chaganti, V., Craven, L., and Fang, D., "Wireless Body AreaNetworks: Toward a Wearable Intranet", National ICT, Australia, 2011.

[3] Bilstrup, K., "A Preliminary Study of Wireless Body Area Networks”, Technical Report IDE0854, School of Information Science, Computer \& Electrical Engineering, Halmstad University, Sweden, 2008.

[4] Boucouvalas, A.C., Chatzimisios, P., Ghassemlooy, Z., Uysal, M., and Yiannopoulos, K., "Standards for Indoor Optical Wireless Communications”, IEEE Communication Magazine, Volume 53, No. 3, pp. 24-31, 2015. in Optical Wireless Broadband Access Networks”, IEEE Photonics Journal, Volume 3, No. 2, pp. 331-336, 2011.

[6] Wang, K., Nirmalathas, A., Lim, C., and Skafidas, E., "Impact of Crosstalk on Indoor WDM Optical Wireless Communication Systems”, IEEE Photonics Journal, Volume 4, No. 2, pp. 375-386, 2012.

[7] Chow, C., Yeh, C., Liu, Y., and Liu, Y., "Digital Signal Processing for Light Emitting Diode Based Visible Light Communication”, IEEE Photonics Society News Letters, pp. 9-13, October, 2012.

[8] Wang, Z., Yu, C., Zhong, W.-D., Chen, J., and Chen, W., "Performance of a Novel LED Lamp Arrangement to Reduce SNR Fluctuation for Multi-User Visible Light Communication Systems”, Optic Express, Volume 20, No. 4, pp. 4564, February, 2012.

[9] Lin, W.-Y., Chen, C.-Y., Lu, H.-H., Chang, C.-H., Lin, Y.-P., Lin, H.-C., and Wu, H.-W., “10m/500Mbps WDM Visible Light Communication Systems”, Optic Express, Volume 20, No. 9, pp. 9919-9924, 2012.

[10] Baqai, A., Umrani, F.A., and Chowdhry, B.S., "Design, Development and Implementation of the IR Signaling Techniques for Monitoring Ambient and Body Temperature in WBANs”, Mehran University Research Journal of Engineering \& Technology, Volume 33, No. 3, pp. 365-371, Jamshoro, Pakistan, July, 2014.

[11] Komine, T., and Nakagawa, M., "Fundamental Analysis for Visible-Light Communication System using LED Lights”, IEEE Transactions on Consumer Electronic, Volume 50, No. 1, pp. 100-107, February, 2004.

[12] Cossu, G., Corsini, R., and Ciaramella, E., "Indoor HighSpeed Optical Wireless Communications: Recent Developments”, 16th International Conference on Transparent Optical Networks, pp. 1-4, Graz, 6-10 July, 2014.

[13] Chow, C.W., Yeh, C.H., Liu, Y.F., and Huang, P.Y., "Mitigation of Optical Background Noise in LightEmitting Diode (LED) Optical Wireless Communication Systems", IEEE Photonics Journal, Volume 5, No. 1, pp. 7900307-7900307, February, 2013.

[14] Shridhar, A., "Visible Light Communication”, PhD Thesis, Worcester Polytechnic Institute, 2015.

[15] Choi, H.S., Kang, S.Y., Cho, S.J., Oh, I.-Y., Shin, M., Park, H., Jang, C., Min, B.-C., Kim, S.-I., Park, S.-Y., and Park, C.S., "Spin Nano-Oscillator-Based Wireless Communication”, Science Report, Volume 4, June, 2014.

[16] Prince, S., and Vibin, A.M., "Optical Wireless Audio Communication Using LED Lighting System”, Wireless Prospectus Communication, Volume 86, No. 3, pp. 11591168, February, 2016.

[17] Hussain, B., Li, X., Che, F., Patrick Yue, C., and Wu, L., "Visible Light Communication System Design and Link Budget Analysis", Journal of Light Technology, Volume 33, No. 24, pp. 5201-5209, December, 2015. 